\title{
Automatic Load Detector Design to Determine the Strength of Pedestrian Bridges Using Load Cell Sensor Based on Arduino
}

\author{
Kurnia Paranita Kartika Riyanti ${ }^{1}$, Ismail Kakaravada ${ }^{2}$, and Abdussalam Ali Ahmed ${ }^{3}$ \\ ${ }^{1}$ Faculty of Information Technology, Balitar Islamic University, Blitar, Indonesia \\ ${ }^{2}$ Department of Mechanical Engineering, Prasad V. Potluri Siddhartha Institute of Technology, Vijayawada, India \\ ${ }^{3}$ Department of Mechanical and Industrial Engineering, Bani Waleed University, Libya \\ Corresponding author: Kurnia Paranita Kartika (e-mail: kurnia.paranitha@gmail.com ).
}

This work is supported by Research Institute and Community Service of Balitar Islamic University

\begin{abstract}
The basic requirement that must be met in constructing a bridge is resilience. This resilience depends on the bridge's support when the bridge's load passes. Loading condition on a bridge is generally dynamic, which can vary according to its crossing conditions. This reason validates difficulties in estimating the lifetime of the bridge. In order to maintain the good condition of the bridge, the estimation of the overloading condition and its effects of overloading on the bridge need to evaluate to keep the bridge durable for that, a bridge load measuring detector is required. This research aims to design an automatic load detector to test the bridge's strength at dynamic loading conditions. The load detector was developed through an Arduino-based load cell sensor. The detector is equipped with an I2C LCD display mechanism that can display the load on the bridge and a buzzer switch with a warning alarm that can alert when the bridge is overloaded. The total sensor mechanism was tested on a miniature wooden bridge with selected loads. During testing, the detector load cell sensors are placed at the bottom of the bridge surface with a running load. The readings are considered recorded for several load cells at dynamic loading conditions. The research work was carried out on the bridge using various load ranges from 100 grams to 25 kilograms on load cells at various positions. From the experimentation, it has been noticed that the load cell has displayed a smaller value than the actual value due to the load distribution over the bridge structure. From the experimental data, the average error rate is $4.67 \%$; hence the developed sensor system is more suitable for practical application to evaluate the damage of the bridge. It also concluded that the detector is more effective in evaluating dynamic loading conditions to prevent bridge damage.
\end{abstract}

INDEX TERMS Load Cell HX711, Auto Detector, Arduino, Bridge Strength.

\section{INTRODUCTION}

As an archipelagic country, Indonesia has a unique topography in the form of lands separated by waters and rivers. This condition makes Indonesia needs bridges as one of the critical infrastructures in supporting the economy in Indonesia. Various bridges used in Indonesia include steel frame bridges, light steel frames, wooden and bamboo. The type of bridge-building material chosen is determined by the bridge user and the user's capability in both number and load $[1]$.
The role of bridges is essential inland transportation; in connection with its crucial role, bridge construction must meet various standards. One of the characteristics that must be met while constructing a bridge is the bridge's ability to take the weight of both people and vehicles going across it and the strain conditions on the bridge. Some of the damages of bridges were caused by underground construction (foundations) and the surrounding soil condition that experienced changes in shape. The cause of this change in shape is due to internal factors such as construction and 
foundation or external factors such as temperature, pressure/strain, and earthquake [2]. The aging structure of the bridge, uncertain environmental conditions, and the added load of vehicles passing through it are subjects that must be monitored in bridge maintenance [2]. This reason validates it is necessary to monitor bridges and detect structural deformations caused by routine operations or environmental impacts such as bridge age, daily traffic, and location were influential in determining condition ratings between different districts and structure types [3]. In addition, monitoring the overall structure needs to be carried out after extreme climatic conditions like earthquakes [4]. To anticipate bridge performance problems, maximize the bridge's lifespanased on the bridge frame material, and avoid bridge damage due to load overload, routine monitoring and evaluation of the integrity of civil structures using sensor network technology or wired or wireless communication is required [5]. In the current study, an automatic detector was introduced to determine the strength of the bridge when given running at dynamic loading conditions. This load cell detector utilizes a sensor with a maximum capacity of $25 \mathrm{~kg}$ in a total of four which are mounted under the bridge surface in the minutest system or tiny form. In actual use in bridge construction, scaling will be used both in terms of bridge dimensions and load cell sensor capacity.

$\mathrm{X}$. Zhuang evaluated the load test using an ARM9-based embedded bridge stress monitoring system. The system uses the measuring principle of vibrating wire sensors to collect bridge stress change, and the Zigbee will complete the wireless transmission of data. The stress acquisition module driver was analyzed and designed under Linux. Depending upon the embedded GUI solutions-t, a highly effective, stable GUI application has been designed [6]. Aisha B. Rahman presents an ARM9-based embedded bridge stress monitoring system. The system uses the measuring principle of vibrating wire sensors to collect bridge stress change, and the Zigbee has completed the wireless transmission of data. The stress acquisition module driver was analyzed and designed under Linux. Depending upon the embedded GUI solutions-Qt Embedded, a highly effective, stable GUI application has been designed. The new design is suitable for real-time bridge stress monitoring, thus making it important for low-cost and portable systems [7]. The vibration signals are very important in the bridge health monitoring system because the variations in bridge vibration frequency indicate the changing of the bridge structure state. J. Huang et al. conducted an effective method for application vibration signal analysis in the bridge health monitoring system. The vibration signals are recorded through a wireless sensor network. Independent component analysis (ICA) theory, bandpass filter (BPF) technique, and spectral analysis are applied to analyze the monitoring data of bridge vibration signals in the bridge health monitoring system through denoising to enable classification and feature extraction from the vibration signals. Meanwhile, compared with conventional methods, the proposed method can obtain better results to analyze the vibration signals of bridge structure in health monitoring [8].

Seno Adi Putra presented their results in developing a vibration-based bridge condition assessment system that identifies the natural frequency and shape of the bridge vibration. The experimental results disclose that, that the system can measure natural frequencies with values that have good agreement with the results of finite element analysis (FEA), and based on the calculation of the modal assurance criteria (MAC), the results of the system built have an excellent correlation with FEA [9]. Pooja K. Patil aims to detect the health condition of the bridge, in this case, the deformation of the bridge construction. An accelerometer sensor was opted to conduct the experimentation. The data is generated by using the sensor is recorded in real-time according to the requirement. The results obtained are sensor data is more accurate up to 40 meters [10]. The previous literature survey concludes that some researchers are still focusing on developing a load cell sensor for testing loads and calculating weights. Still, there is a literature gap on dynamic loading evaluation and estimation of the lifetime of bridges. The current research focuses on the development of load cell sensors by using the Arduino system to evaluate the load distribution on a structure.

\section{MATERIALS AND METHODS}

\section{A. RESEARCH DEVELOPMENT METHOD}

Researchers carried out many developments procedures to realize the design of an automatic detector to test the bridge strength load using a load cell sensor. The research and development cycle briefly consists of studying research findings related to the product to be developed, developing it, conducting testing, and revising it to correct the deficiencies found. The flow of the research was developed by following the Borg and Hall model (1989:775) as shown in FIGURE 1.

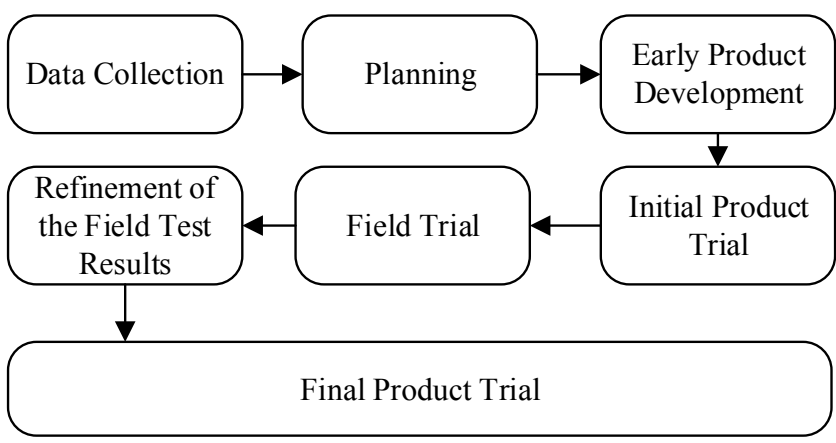

FIGURE 1. Research and Development Method

\section{B. EXPERIMENTAL SETUP}

1) Materials and Tool

In this study, the components used are four HX711 load cell sensors with a maximum weight specification of $25 \mathrm{~kg}$ as a 
load counter sensor one microcontroller, namely the Arduino UNO R3 type, which functions as a load value processor. This Arduino monitored the HX711 load cell sensor, 1 LCD 16x2 I2C, which displays the weight value of the load, and a buzzer that functions as an alarm if the miniature bridge's load exceeds the limit of 25 kilograms.

\section{2) Experimentation}

This study tested two types of loads on miniature bridges for pedestrians. The first test uses a static load; namely, the load is placed directly on the bridge's surface. Furthermore, it will detect which load cell will read the load, and the accuracy of the reading results will also be checked. Furthermore, the second test is the walking load on the surface of the bridge; the walking load test will check the accuracy of the load cell readings and the tendency of the load to lead to any load cell.

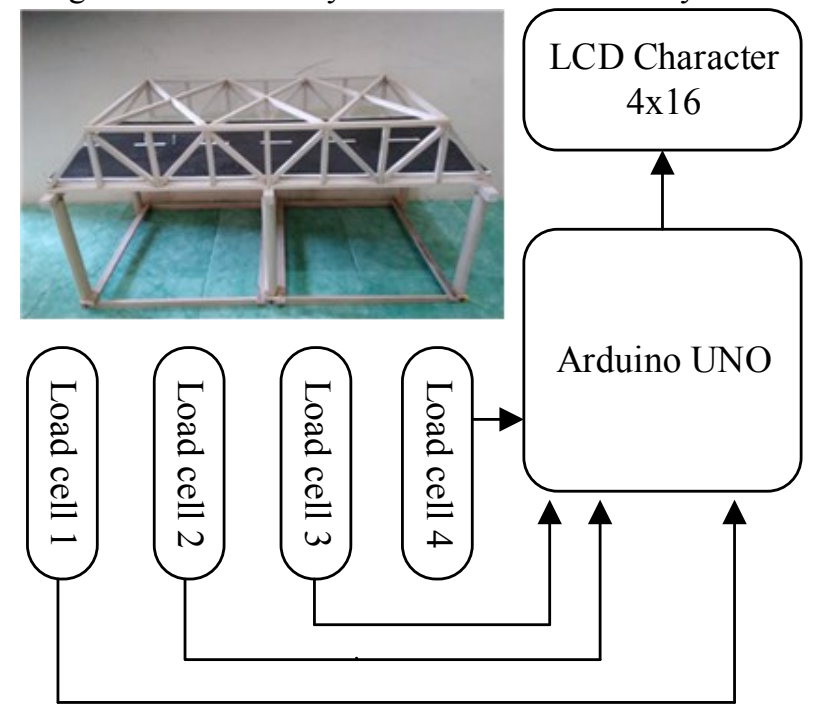

FIGURE 2. Block Diagram of Bridge Load Test Detector

\section{THE DIAGRAM BLOCK}

Based on the block diagram in FIGURE 2, all components in this tool are connected to a voltage source from Arduino UNO R3. The load cell sensor will read the value of the load supported by the bridge and then send it to the microcontroller for processing. The processed data is displayed on the LCD; both the reading of each load cell and the total load received by the four load cells will also be recorded. Furthermore, if it has been overloaded, which is above $50 \mathrm{~kg}$, the buzzer will sound, which indicates the load cannot add the bridge. In realizing the actual bridge construction later, people or pedestrians are prohibited from crossing through it in this condition. If the load is still within the limit value that the sensor can support. The HX711 load cell reading sensor requires +5 VDC and ground input voltage. The output of the HX711 is digital data which is connected to digital pins 2, 3, 4, and 5 on the Arduino UNO R3 microcontroller. The output data from the HX711 sensor in the form of digital data connected to digital pin ten was read and displayed on the I2C LCD screen. The load reading by the HX711 sensor when less than 25 kilograms will be displayed on the LCD, but if the load reading is more than 25 kilograms, the buzzer has sound. This indicates that the bridge is overloaded and cannot be added to. In the installation of a load cell must pay attention to the part connected to the microcontroller and the part connected to the load. The part that is connected to the load has an arrow down, which means that the installation of this load must not be reversed so that it can be read properly.

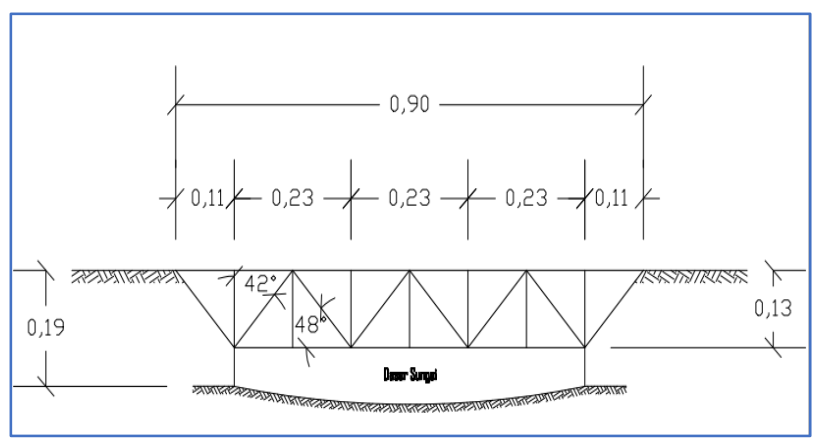

FIGURE 3. Cross-Section of Miniature Bridge

In FIGURE 3, a constructional image of a miniature bridge was used for load testing. The miniature bridge has dimensions of $90 \mathrm{~cm}$ long and $42 \mathrm{~cm}$ wide; the height of the miniature bridge is $40 \mathrm{~cm}$ using four foundations. The angle between the nodes on the bridge is set at $42^{\circ}$ and the node height is $13 \mathrm{~cm}$. the distance between the foot of the bridge and the end of the bridge is $11 \mathrm{~cm}$, while the distance between the nodes is $23 \mathrm{~cm}$.

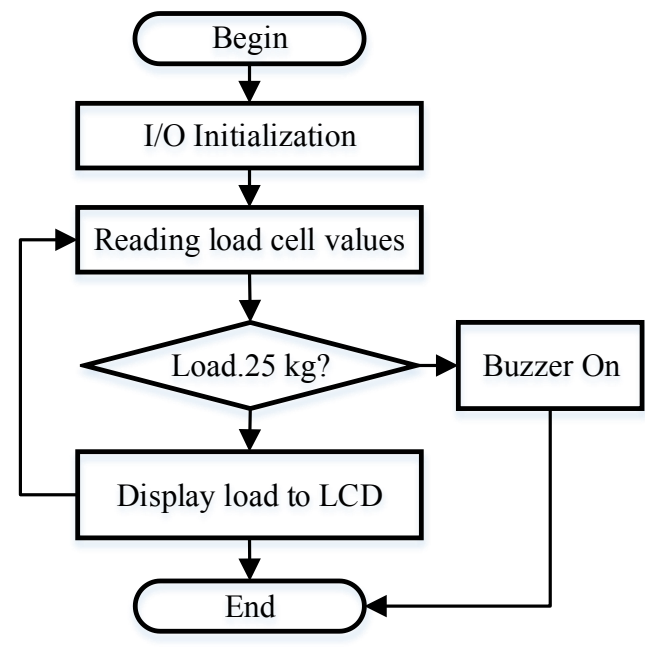

FIGURE 4. System Flowchart

\section{FLOWCHART}

FIGURE 4 shows a flow chart of the system. The first stage is the input and output initialization process; at this stage, it is ensured that all devices are working properly in normal 
conditions. Furthermore, each load cell sensor subjected to a load will read the load value and send information to the Arduino. While reading the load by the load cell sensor, the results will be displayed on the $\mathrm{I} 2 \mathrm{C}$ LCD both from each load cell and from the combination of the four load cells. If the read load exceeds 25 kilograms, the buzzer will be activated as a sign that the bridge is overloaded, and for the time being, there should be no additional load on the bridge. This process will repeat continuously as long as the detector is activated.

III. RESULTS

This research begins with assembling the tool according to the design and flow of the system; after carrying out the assembly process, it continues with small-scale testing at the civil engineering laboratory of the Islamic University of Balitar. The detector test is carried out on a miniature wooden bridge for pedestrians, which is designed to resemble the original shape of the bridge. The results obtained are as follows:

\section{A. MICROCONTROLLER DESIGN}

The automatic detector generated for testing the bridge load is as shown in FIGURE 5. The placement of the sensor is on the outside of the microcontroller box because it is connected directly to the load to be calculated, while the Arduino, I2C $\mathrm{LCD}$, and buzzer are placed in the box for easy portability and transfer.

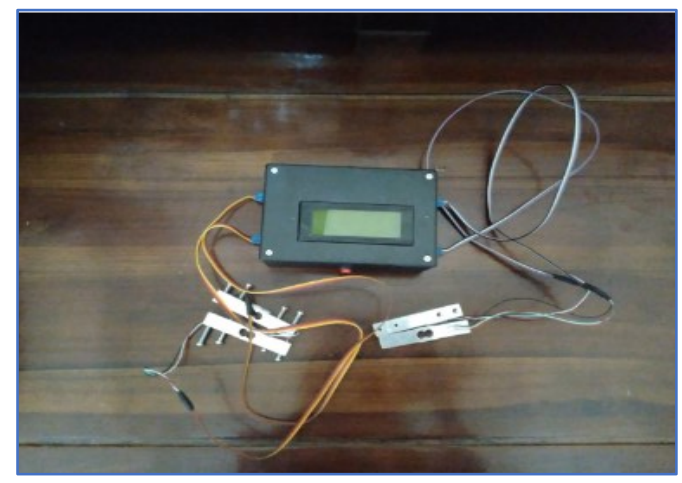

FIGURE 5. System Detector

The power supply is obtained from an adapter and a serial cable connected to PLN electricity. If there is an emergency condition or will be taken to an open place that does not allow a power source, the power supply can be obtained from batteries or batteries. This detector is classified as energyefficient because using one battery can activate the device for up to 5 days if used non-stop. In addition, another advantage is that all components can be connected to the voltage on the microcontroller so that only one voltage source is needed.

\section{B. MINIATURE BRIDGE}

A miniature bridge was made to test the load using an automatic detector as shown in FIGURES 6 and FIGURE 7. The materials used to make the miniature are light wood and plywood. The bridge is made adapted to the actual conditions with a size of 1:10 scaling.

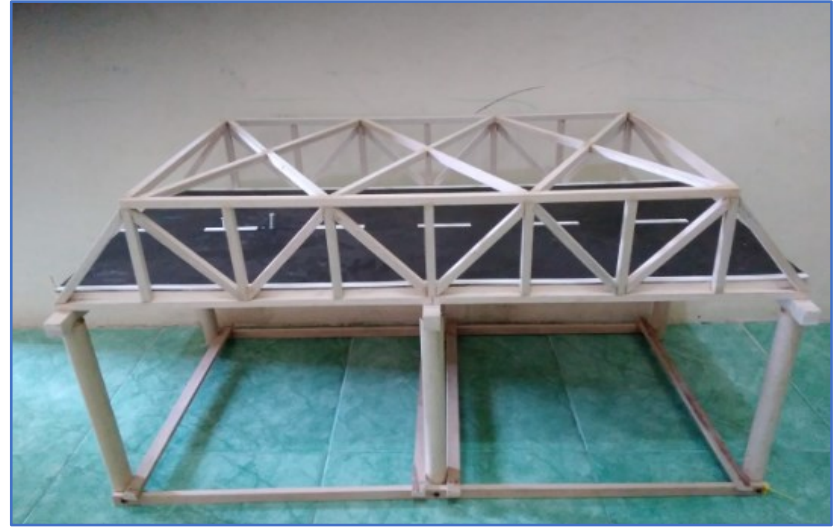

FIGURE 6. Miniature Bridge Cross Section

The automatic detector is installed, as shown in Figure 7. A series of Arduino controllers, LCDs, and buzzers are placed on the middle side of the bridge side. Then, four HX711 load cell sensors are placed at the bottom center of the bridge surface, as shown in the picture. The purpose of placing the sensor in the middle is to reach readings from various sides. Furthermore, the detector must be connected to a power source before being used.

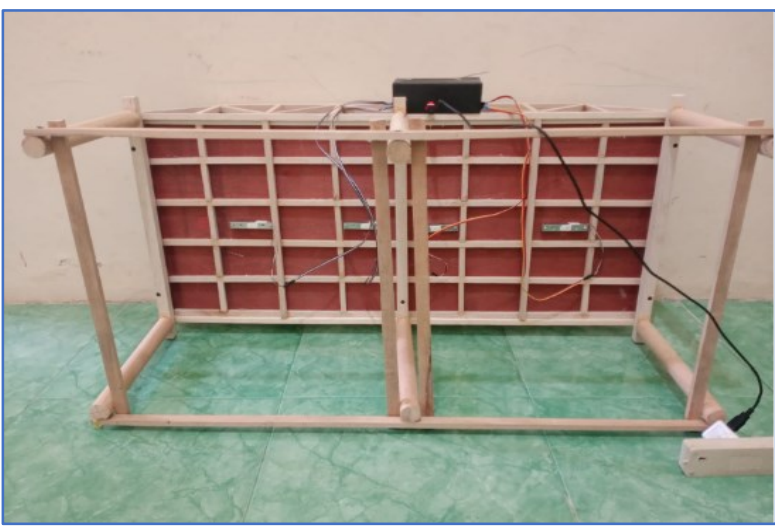

FIGURE 7. Installing the Detector on a Miniature Bridge

\section{TESTING OF LOAD CELL HX711}

Tests on this component are carried out to know how it works simultaneously to determine whether the sensor can measure the weight according to the actual weight. The load cell test emphasizes that it has worked well, and readings have been conformity. The measurement uses chunks of paper with random weights ranging from 40 to 70 grams. The accuracy of the reading is also influenced by the position of the load placement and the placement of the sensor in accordance with the technical instructions. Before use, the load cell must be calibrated. The scale calibration process is carried out by comparing the measured results with the known weight of a calibrating load. The load cell is used as a digital weight sensor. The loadcell calibration process with Arduino uses the two-load method. How to calibrate loadcell with this two-load method produces two variables: scale and offset. 


\section{SYSTEM TESTING WITH STATIC LOAD}

This study has two test scenarios: a stationary load and a dynamic load. In the test with a stationary load, weights of various sizes and weight variations are used. The weights as the measurement object are placed directly above the sensor, as shown in FIGURE 8.

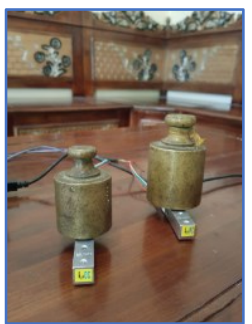

(a)

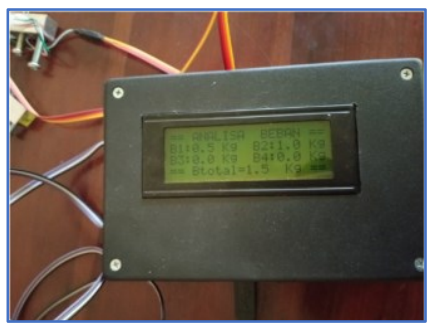

(b)
FIGURE 8. Load cell testing (a) stationary test and (b) sensor reading results.

In testing with a static load, it can be seen that the readings of the load cell sensor correspond to the actual weight of the weights. As shown in FIGURE 8, the reading of the total load is $1.5 \mathrm{~kg}$ according to the actual weight of the weights.

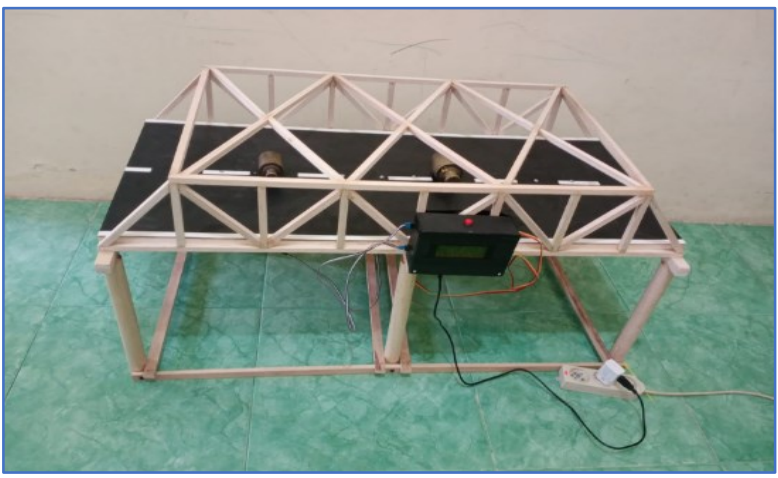

FIGURE 9. Running Load Test

\section{E. SYSTEM TESTING WITH DYNAMIC LOADING}

In testing with a walking load, weights of various sizes and weight variations are used. The weights as measurement objects are run on the bridge's road surface, as shown in FIGURE 9. In testing with a running load, it can be seen that the results of the load cell sensor readings tend to vary from 1 load cell to another load cell. The results of the test with a running load have discrepancies in readings because the position of the load is always changing due to running. Generally, this discrepancy occurs because the load is not fully supported by one of the load cell sensors, so what is read on the sensor is only a point load, for a moment where the heaviest load is received by the load cell.

Based on the results of the tests that have been carried out, they can be summarized in TABLES 1 and TABLE 2.
TABLE 1

Test using a static load

\begin{tabular}{cccc}
\hline No & $\begin{array}{c}\text { Load } \\
\text { (Grams) }\end{array}$ & $\begin{array}{c}\text { Load Cell } \\
\text { Result (Grams) }\end{array}$ & \% Error \\
\hline 1 & 100 & 98 & 2 \\
\hline 2 & 250 & 255 & 2 \\
\hline 3 & 500 & 500 & 0 \\
\hline 4 & 1000 & 1000 & 0 \\
\hline 5 & 1500 & 1500 & 0 \\
\hline 6 & 2000 & 2000 & 0 \\
\hline 7 & 2500 & 2500 & 0 \\
\hline 8 & 3000 & 3000 & 0 \\
\hline 9 & 3500 & 3500 & 0 \\
\hline 10 & 4000 & 4000 & 0 \\
\hline 11 & 5000 & 5000 & 0 \\
\hline 12 & 10000 & 10000 & 0 \\
\hline 13 & 15000 & 15000 & 0 \\
\hline 14 & 20000 & 20000 & 0 \\
\hline 15 & 25000 & 25000 &
\end{tabular}

In TABLE 1, the test results on a stationary load have been summarized. The position of the load is placed directly above the detector to determine whether the load reading by the load cell sensor is appropriate or not. The test results using a static load show the suitability data for almost all test loads. A load cell with a maximum test capacity of 25 kilograms can properly read loads ranging from 100 grams to 25 kilograms. At the load of 100 and 250 grams, there is an error of $2 \%$. The test object is placed on the sensor directly, and the display of the reading results has a delay of about five milliseconds from placing the test object on the sensor. The suitability data for several test loads are obtained from the test results using dynamic (running) loads. In the load cell with a maximum test capacity of 25 kilograms and the load runs on a miniature bridge trajectory, there are errors ranging from $2 \%$ to $8.6 \%$. The largest error percentage on the running test load is 2 kilograms, and the smallest error on the running test load is 250 grams. The average error of 15 times of testing is $3.4 \%$. The readings are variable for each load cell at running load because the readings refer to the load cell that receives the most load from the test object. The test object is run on the bridge track, and the display of the reading results has a delay of about three milliseconds.

\section{RESULTS AND DISCUSSION}

An automatic detector is produced which is used to test the strength of the bridge if it is given a running load. The load object is placed on a miniature wooden bridge by running it on the surface of the bridge. At the bottom of the bridge, 4 load cells are installed to know the distribution of the running load that is read on the detector. The mechanism for testing 
TABLE 2

Test using running load

\begin{tabular}{|c|c|c|c|c|c|c|c|}
\hline No & $\begin{array}{l}\text { Load Test } \\
\text { (Grams) }\end{array}$ & $\begin{array}{l}\text { Load Cell I } \\
\text { (Grams) }\end{array}$ & $\begin{array}{l}\text { Load Cell II } \\
\text { (Grams) }\end{array}$ & $\begin{array}{c}\text { Load Cell III } \\
\text { (Grams) }\end{array}$ & $\begin{array}{c}\text { Load Cell IV } \\
\text { (Grams) }\end{array}$ & $\begin{array}{c}\text { Sum } \\
\text { (Grams) }\end{array}$ & $\begin{array}{l}\text { \% Error } \\
\text { (Grams) }\end{array}$ \\
\hline 1 & 100 & 80 & 0 & 15 & 0 & 95 & 5 \\
\hline 2 & 250 & 0 & 125 & 120 & 0 & 245 & 2 \\
\hline 3 & 500 & 0 & 25 & 100 & 350 & 475 & 5 \\
\hline 4 & 1000 & 25 & 200 & 0 & 750 & 975 & 2.5 \\
\hline 5 & 1500 & 58 & 750 & 560 & 23 & 1391 & 7.3 \\
\hline 6 & 2000 & 0 & 1800 & 0 & 28 & 1828 & 8.6 \\
\hline 7 & 2500 & 0 & 0 & 385 & 2000 & 2385 & 4.6 \\
\hline 8 & 3000 & 95 & 0 & 0 & 2880 & 2975 & 0.8 \\
\hline 9 & 3500 & 0 & 1923 & 280 & 1257 & 3460 & 1.1 \\
\hline 10 & 4000 & 236 & 993 & 2315 & 575 & 4119 & 2.9 \\
\hline 11 & 5000 & 565 & 894 & 1965 & 1534 & 4958 & 0.8 \\
\hline 12 & 10000 & 210 & 5701 & 3876 & 451 & 10238 & 2.3 \\
\hline 13 & 15000 & 498 & 8632 & 6271 & 0 & 15401 & 2.7 \\
\hline 14 & 20000 & 0 & 390 & 9880 & 8970 & 19240 & 3.8 \\
\hline 15 & 25000 & 0 & 9300 & 11839 & 4300 & 25439 & 1.7 \\
\hline
\end{tabular}

the load runs by preparing a load whose weight varies from 100 grams to 25 kilograms, then it is run on the surface of a miniature bridge. From several tests, information is obtained that the load that is read while it is running tends to vary from one load cell to another. The readings displayed on the LCD are the result of the accumulation of the four sensors. There have not been tests of bridge strength based on the distribution of dynamic loads. This research is expected to be able to contribute to the development of detector technology to be applied to the real-time evaluation of the bridges. However, this research still requires a lot of new development due to the limitations of the test equipment so that the scale is still in the minimum form of the system. Several factors can cause a mismatch of readings on dynamic loading conditions, among others, because the load read by the sensor is a point load that causes changes in a relatively short time. In addition, all loads are not supported by the load cell, but some of the load is supported by bridge piers or bridge boards.

\section{CONCLUSION}

From the experimentation, a salient conclusion was drawn. The automatic load detector was successfully developed to evaluate the bridge's strength at static and dynamic loading conditions. The experimental results show the effective transformation of the load is not taking place due to the load distribution among the bridge structure. The experimental results analysis discloses that a $4.67 \%$ error was encountered in detecting load at the dynamic condition at several loading conditions. Finally, the developed Arduino-based load cell sensor is more effective in evaluating the static and dynamic loading condition of the bridge strength for estimation of the life span of the bridge.

\section{REFERENCES}

[1] S. A. Putra, B. R. Trilaksono, M. Riyansyah and D. S. Laila, "Multiagent Architecture for Bridge Capacity Measurement System Using Wireless Sensor Network and Weight in Motion," IEEE Transactions on Instrumentation and Measurement, pp. 1-14, 2021.

[2] S. Clonts, L. Cooley and P. Freitag, "Virginia Bridge Deterioration Factors," Systems and Information Engineering Design Symposium (SIEDS), vol. 10, no. 1109/SIEDS.2019.8735618., pp. 1-5, 2019.

[3] H. Jun, W. Qin, Z. Chang Jun and C. Dai Ping, "Research on reasonable structure forms of pedestrian suspension bridges," International Conference on Electric Technology and Civil Engineering (ICETCE), vol. 10, no. 1109/ICETCE.2011.5775879, pp. 613-616, 2011.

[4] A. M. Chyad, O. Abudayyeh, F. Zakhil and O. Hakimi, "Deterioration Rates of Concrete Bridge Decks in Several Climatic Regions," IEEE International Conference on Electro/Information Technology (EIT), vol. 10.1109/EIT.2018.8500, pp. 65-68, 2018.

[5] J. Avendano, L. D. Otero and C. Otero, "Optimization of Sensor Placement in a Bridge Structural Health Monitoring System," IEEE International Systems Conference (SysCon), vol. 10.1109/SysCon48628.2021.9447077., pp. 1-5, 2021.

[6] X. Zhuang, L. Zhang, M. Fang and H. Wang, "An Embedded System of Bridge Stress Monitoring Based on ARM9 and Zigbee," International Conference on Electrical and Control Engineering, vol. 10.1109/iCECE.2010.1211., pp. 5007-5010, 2010. 
[7] A. Rahman, S. Kamal and A. Islam, "Bridge Strength Preservation by Automatic Traffic Density Control: an IoT Application," 1st International Conference on Advances in Science, Engineering and Robotics Technology (ICASERT), vol. 10.1109/ICASERT.2019.8934520, pp. 1-5, 2019.

[8] J. Huang, H. Ogai, C. Shao, J. Zheng, I. Maruyama and S. Nagata, "On vibration signal analysis in Bridge Health Monitoring System by using Independent Component Analysis," Proceedings of SICE Annual Conference 2010, pp. 2122-2125, 2010.

[9] S. A. Putra, B. R. Trilaksono, M. Riyansyah and D. S. Laila, "Intelligent Sensing in Multiagent-Based Wireless Sensor Network for Bridge Condition Monitoring System," IEEE Internet of Things Journal, vol. 6, no. 3, pp. 5397-5410, 2019.

[10] P. Patil and S. Patil, "Structural health monitoring system using WSN for bridges," International Conference on Intelligent Computing and Control Systems (ICICCS), vol. 10.1109/ICCONS.2017.8250746, pp. 371-375, 2017.

[11] J. Purdum, "Beginning C for Arduino," in earn C Programming for the Arduino., 2015.

[12] AASHTO, "Bridge Design Specifications," in Bridge Design Specifications 6th Edition, Washington, AASHTO, 2012.

[13] Z. Chang-Zun, C. Dai-Ping, Q. Xiao and Z. Chang-Sheng, "Research on loads and performance of Guangyuan mountainous pedestrian suspension bridges," International Conference on Electric Technology and Civil Engineering (ICETCE), vol. 10.1109/ICETCE.2011.5774261, pp. 25102513, 2011 .

[14] W. Y. Song, S. H. Rho and Y. K. Kwag, "Automatic bridge detection scheme using CFAR detector in SAR images," 3rd International Asia-Pacific Conference on Synthetic Aperture Radar (APSAR), pp. 1-4, 2011.

[15] B. Zhen and F. Han, "A study for the lateral vibration of the cable-stay bridge induced by pedestrians," International Conference on Electric Technology and Civil Engineering (ICETCE), vol. 10.109/ICETCE.2011.5775319., pp. q9031906, 2011.

[16] W. Q. Z. C.-j. C. D.-p. Q. X. a. Z. C.-s. Hu Jun, "Research on reasonable structure forms of pedestrian suspension bridges," International Conference on Electric Technology and Civil Engineering (ICETCE), vol. 10.1109/ICETCE.2011.5775879, pp. 613-616, 2011.

[17] B. Z. Yong Xu, Zhixiang Zhou, "Electrical and Mechanical Character of Smart Film for Crack Monitoring of Concrete Bridges," Southwest Jiaotong University, Chongqing, 2010.

[18] Y. Li, H. Wei, Z. Guo and B.-C. Chen, "Design and implement of the urban bridge cluster monitoring system," International Conference on Electrical and Control Engineering, vol. 10.1109/ICECENG.2011.6057589., pp. 2107-2110, 2011.

[19] T. R. Lydon, "Development of a Bridge Weighted In Motion Sensor: Performance Comparison using Fiber Optic and Electric Resistance Strain Sensor Sistem," IEEE Sensor Jurnal, vol. 14, no. 12, pp. 4284-4296, 2014.

[20] A. Wahab and D. Roeck, "Damage Detection in Bridges Using Modal Curvatures: Application to A Real Damage Scenario," Journal of Sound and Vibration, vol. 226, no. 2, pp. 217-235, 1999.
[21] T. Dutta, "Damage Detection in Bridges Using Accurate Modal parameters," Finite Elements in Analysis and Design, vol. 40, pp. 287-304, 2002.

[22] A. A. T. E. M. H. A. d. A. B. ". A. B. Noe, "Structural Health Monitoring Using Wireless Sensor Networks: A Comprehensive Survey," IEEE Communicatuon Surveys and Tutorials, vol. 19, no. 3, pp. 1403-1423 , 2017.

[23] P. S. T. Pievanelli, "Dynamic wireless sensor networks for real time safeguard of workers exposed to physical agents in constructions sites," IEEE Topical Conference on Wireless Sensors and Sensor Networks (WiSNet, vol. 10.1109/Wisnet.2013, pp. 55-57, 2013.

[24] M. Kumar, K. Pattanaik, B. Yadav and R. Herma, "Optimization of Wireless Sensor Networks inspired by Small World Phenomenon," IEEE 10th International Conference on Industrial and Information Systems (ICIIS), vol. 10.1109/ICIINFS.2015, pp. 66-70, 2015.

[25] Z. Xu and Z. Wu, "Energy Damage Detection Strategy Based on Acceleration Responses for Long-Span Bridge Structures," Engineering Structures, vol. 29, no. 4, pp. 609-617, 2007.

\section{BIOGRAPHY}

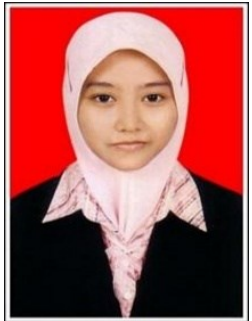

The author was born in Blitar City in 1988. He received his bachelor's and master's degrees from the Sepuluh Nopember Institute of Technology, Surabaya, majoring in Electrical Engineering. The author graduated with a bachelor's degree in 2010 and a master's degree in 2018. Since graduating from a master's degree until now, the author has worked as a lecturer in the Department of Electrical Engineering and Computer Systems, Balitar Islamic University. His research interests include sensors and actuators, automated control systems, Internet of Things and Digital Signal Processing and Antenna Technology. The author is actively conducting research and community service either funded by the Ministry of Education and culture or an Internal grant from the University where he works. The author is also active as a reviewer in several Open Journal Systems (OJS) at several universities. The author has won the Technological Innovation competition at the Blitar City level and has guided various student competitions on a local to national scale. 


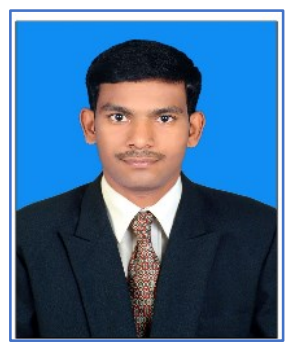

Dr. Ismail Kakaravada, working as an Assistant Professor in the Department of Mechanical Engineering at Prasad V. Potluri Siddhartha Institute of Technology, Kanuru, Vijayawada. He graduated in Mechanical Engineering at Jawaharlal Nehru Technological university, Hyderabad, Telangana, India. He secured Master of Technology in Production Engineering at Sree Venkateshwara University college of Engineering, Tirupati, Andhra Pradesh, India. He is Pursuing Ph.D. in materials and manufacturing at Jawaharlal Nehru Technological university, Anantapuramu, Andhra Pradesh, India. He is in teaching profession for more than ten years. He has presented 20 number of research papers in various National and International Journals, Conference and Symposiums. His main research area of interest includes composite Materials and Manufacturing.

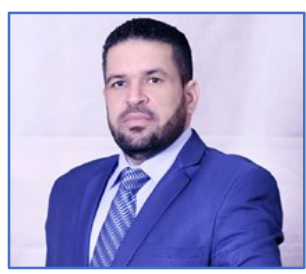

Abdussalam Ali Ahmed received the B.Eng. and M.Sc. degrees from Tripoli University in 2002 and 2005. and the $\mathrm{PhD}$ degree from Okan University, Istanbul, Turkey 2017. He is working with Bani Waleed University as head of the mechanical and industrial engineering department. His areas of interest include Mechatronics, mechanical engineering, control systems, and vehicles dynamic. 